\title{
Evaluation of Maleated Polyethylene in Natural Rubber and Teline monspessulana Flour Composites
}

\author{
Oscar Palacio $^{1}$, Emilio Delgado $^{1}$
}

1. Universidad Militar Nueva Granada Bogotá D.C, Colombia

\author{
Authors: \\ O. Palacio
}

Tel: 6500000 Ext 1283

*E-mail: oscar.palacio@unimilitar.edu.co

\section{E. Delgado}

*E-mail: arnoldo.delgado@unimilitar.edu.co

E-mail for correspondence: articulopublish@gmail.com

\begin{abstract}
.
The effect of the addition of maleated polyethylene (MAPE) to compounds of natural rubber (NR) and Telinne monspessulana flour (TMF) previously mercerized was investigated. Two factors were analyzed: A. concentration of MAPE with five levels 2; 4; 6; 8; 10 phr (parts per hundred rubber), B. concentration of TMF with two levels 25 and 40 phr. The effect of MAPE on compatibility between NR and HTM was evaluated by tensile testing the compounds. The mixing was performed in a laboratory scale mill. The test tubes were obtained by cutting or die-cutting crosslinked peroxide sheets, these were obtained during the compression molding process. Analysis indicate that the MAPE coupling agent improved the compatibility between HTM and NR, this effect was evidenced by the values of tensile strength and elongation at break. However, the gel content determination indicates that the addition of $10 \mathrm{phr}$ of MAPE crosslinking decreases due to competition with coupling reaction MAPE - HTM.
\end{abstract}


Key words: NR, MAPE, Telinne Monspessulana, compounds, tensile properties, coupling. INTRODUCTION.

The use of naturals fibers like reinforcing charges in polymerics materials have increasingly peaked thanks to their technical advantages, environments terms and economics. The inclination for product development sustainable increasingly positions natural fibers as a great alternative for its availability, diversity and renewability. However, its hydrophobic character limits compatibility with polyolefins and/or elastomers, in a way it is necessary to modify its surface through chemical treatments or the use of coupling agents, that contribute to improve interfacial addition whit the polymer hydrophobic matrix ${ }^{[1-9]}$.

Treatments like the mercerization, acetylation, benzoylation of the fibers among others, are usually performed prior to surface modification with coupling agents such as silanes and graft copolymers as part of the strategy to improve the fiber-polymer interaction and decrease the moisture absorption ${ }^{[10-12]}$. Different investigations had been studied owing to their advantages of high strength-to-weight ratio and good durability ${ }^{[31-33]}$ Particularly, the mercerization of the vegetal fiber increases the tensile strength and the tearing into natural rubber compounds (NR), as reported by Jacob, Thomas, \& Varughese, who investigated the effect of the incorporation of sisal fibers (FS) and oil palm in (NR); the highest values were reached when the fiber content was $30 \mathrm{ph}$. Similar effect was reported by Geethamma, Thomas Mathew, Lakshminarayanan, \& Thomas, when mixing coconut fibers with natural rubber and low-density polyethylene. The tensile strength property reached its highest value when the fiber content reached $25 \%$ by weight.

Regarding to the application of graft copolymers to improve the compatibility of plant fibers with natural rubber, research mentions the use of maleated natural rubber (MANR), which acts as a bridge between the fiber and the elastomer, thus improving the interfacial adhesion and therefore, there is an increase in the mechanical properties of the compound ${ }^{[13-17]}$. Zeng et al., report that the incorporation of MANR in natural rubber compounds with cotton fiber, leads to improve mechanical properties in terms of greater modulus and tensile strength. By 
mixing NR with paper sludge, Ismail, Rusli, \& Azura and Ismail, Rusli, \& Rashid, claim that the addition of MANR increases the tensile strength and fatigue of the compounds, whose effect is attributed to the improvement of the interfacial adhesion between the filling and the rubber in the presence of the compatibilizing agent. Another coupling agent that has been investigated is the maleated polyethylene (MAPE). Sameni, Ahmad, \& Zakaria, used as a compatibilizer in wood flour compounds and natural rubber, finding that there is increase in the modulus of elasticity and tensile strength as the MAPE content increases.

In this study, the effect of the maleated polyethylene (MAPE) was investigated as a coupling agent in natural rubber compounds and Telinne Monspessulana flour (TMF), whose species is invasive of the Colombian Andean Zone. The incorporation of MAPE was carried out during the mixing stage. The compound was reticulated using dicumil peroxide (DCP). The effect of the MAPE content on fiber-rubber compatibility was analyzed by evaluating the tensile properties.

\section{EXPERIMENTAL PART.}

\section{Materials.}

TMF, particle diameter $100-800 \mu \mathrm{m}$, humidity $0.50 \%$. Natural rubber type SMRL, mooney viscosity 40. Maleated polyethylene MAPE, graft rate 0.9 , density $0.95 \mathrm{~g} / \mathrm{cm} 3$, marketed by Hangzhou Uniwise® International Co.Ltd. Process aid: Struktol WB 16®, produced by Struktol®. Irganox 1076 produced by BASF. Dicumyl peroxide DCP, Perkadox® BC FF, purity $99 \%$, produced by Akzo Nobel@.

\section{Methods.}

Experimental design. A completely random bifactorial 2x6 design was performed. Factor A: TMF. with two levels 25 and 40 phr. Factor B: MAPE with six levels 0;2; 4; 6; 8 and 10 phr; 
for a total of twelve formulations. The sum NR +MAPE was taken to 100 parts (phr) and was taken as reference to quantify the ingredients, as seen in Table 1. Antioxidant, process aid and DCP remained constant in all formulas. The output variable was assigned to each of the mechanical properties of the rubber compound. 5 repeats per variable were performed.

Table 1. Formulations. All quantities in phr.

\begin{tabular}{|c|c|l|l|l|l|l|l|}
\hline (A)Levels of TMF & Ingredients & \multicolumn{4}{|l|}{ (B) Levels of MAPE } \\
\cline { 3 - 7 } & & 0 & 2 & 4 & 6 & 8 & 10 \\
\hline \multirow{3}{*}{40} & NR & 100 & 98 & 96 & 94 & 92 & 90 \\
& Antioxidant & 1.0 & 1.0 & 1.0 & 1.0 & 1.0 & 1.0 \\
& Process aid & 1.0 & 1.0 & 1.0 & 1.0 & 1.0 & 1.0 \\
& DCP & 1.0 & 1.0 & 1.0 & 1.0 & 1.0 & 1.0 \\
\hline \multirow{2}{*}{25} & NR & 100 & 98 & 96 & 94 & 92 & 90 \\
\cline { 2 - 7 } & Antioxidant & 1.0 & 1.0 & 1.0 & 1.0 & 1.0 & 1.0 \\
\cline { 2 - 7 } & Process aid & 1.0 & 1.0 & 1.0 & 1.0 & 1.0 & 1.0 \\
\cline { 2 - 7 } & DCP & 1.0 & 1.0 & 1.0 & 1.0 & 1.0 & 1.0 \\
\hline
\end{tabular}

Statistical analysis. The influence of MAPE on the mechanical properties of WPC was analyzed by applying two-factor ANOVA with the program Statgraphics® 5.0 using a 95\% confidence level. The mean comparison test was performed using Tukey HSD.

\section{Preparation of compounds}

Mercerization. The flour TM was treated with $\mathrm{NaOH} 8 \% \mathrm{w} / \mathrm{v}$, for 4 hours at $35^{\circ} \mathrm{C}$, according to the procedure described by Buitrago et al ${ }^{[19]}$.

Mixing. It was made in a laboratory roller mill, capacity $600 \mathrm{~cm}^{3}$. The order of addition was the following, first the natural rubber, then the MAPE, then the mercerized TMF, at the end of the incorporation stage the process aid and the antioxidant was added. The DCP was added three (3) minutes before the end of the stage. The temperature of the mixture was $120 \pm 5^{\circ} \mathrm{C}$, the cycle 12 minutes. 
Pressing. The sheets were obtained by compression moulding. A hydraulic press with heating system was used by means of electrical resistance. The operating parameters were: Mould temperature $160 \pm 1^{\circ} \mathrm{C}$, specific pressure 5.24 MPa, pressing time 6 minutes.

\section{Methods of analysis.}

Gel content. The degree of cross-linking was determined by the Soxhlet technique according to ASTM D 2765-01, method $\mathrm{A}^{[20]}$.

Stress Tests. The test pieces were obtained by the die-cutting process, with type B geometry according to ASTM D412-06a ${ }^{c}$. The tensile tests were carried out on a universal machine Shimadzu® AGS-X. Test parameter: displacement speed $50 \mathrm{~mm} /$ minute, temperature $24{ }^{\circ} \mathrm{C}$, relative humidity $45 \%$. Five test pieces were used for each formula.

Hardness. The determination of hardness was made according to ASTM D2240-05 ${ }^{[22]}$. One type A type INSIZE® hard-meter was used. Five (5) measurements were made per test.

\section{Results and analysis.}

Content of the gel

This technique is used to quantify the percentage of polymer chains that are cross-linked. The MAPE factor affects the gel percentage differently at level $25 \mathrm{phr}$ and $40 \mathrm{phr}$ of the TMF factor as seen in Figure 1.

The NR compounds with $25 \mathrm{phr}$ of fiber had a slight increase of $\%$ of gel between the 4-8 phr levels of MAPE. From 8 phr of MAPE there is a further decrease of the gel content being this percentage similar to the compound without coupling agent (level 0 of MAPE). In $2 \mathrm{phr}$ of MAPE there was a significant decrease in gel content. In compounds made with $40 \mathrm{phr}$ of $\mathrm{TMF}$, there is a slight increase in gel content from 2 to $8 \mathrm{phr}$ of MAPE. At level $10 \mathrm{phr}$ the 
percentage of gel decreased significantly, with respect to the compound without MAPE. (level 0 of MAPE).

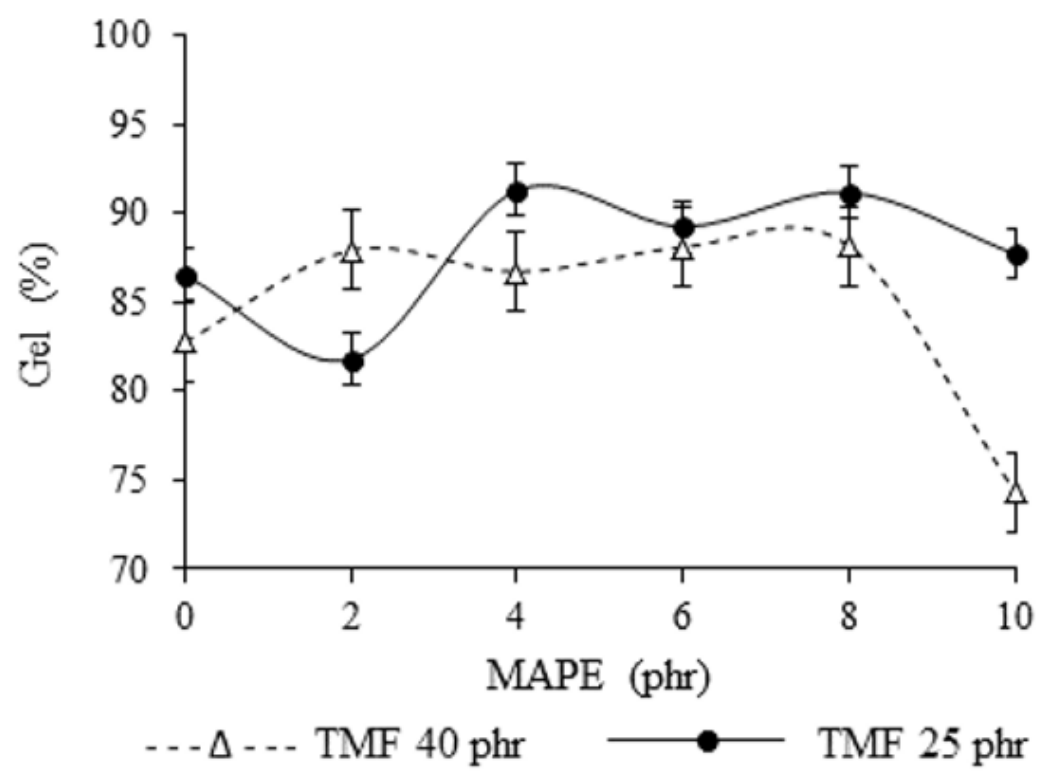

Figure 1. Percentage of gel in NR compounds. Effect of MAPE and TMF content.

The decrease in gel content may be evidence of interference of the coupling reaction (MAPE TMF) with the reticulation reaction (NR-NR via peroxide). This effect found in this paper is consistent with other investigations in which it is stated that the coupling reaction between the MAPE functional groups with the hydroxyl groups of flour negatively affect the crosslinking density of polymers with $\mathrm{DCP}^{[23-25]}$. If it is required to formulate a compound with MAPE level at $10 \mathrm{phr}$, it will be necessary to increase the content of DCP above $1 \mathrm{phr}$ to maintain cross-linking density.

\section{Mechanical properties.}

Young's modulus

The Young's modulus of the rubber compound is formed by the contribution of the NR, TMF, MAPE modules, the influence of the mixing conditions (shear, temperature and time) and the cross-linking density. The mixing process decreases the viscosity of the NR compound and therefore, has a direct consequence in the reduction of its rigidity. Theoretically the plant 
fiber module has values between 500-2500 Mpa. The coupling agent module was measured in the laboratory and its value was $425 \mathrm{Mpa}$.

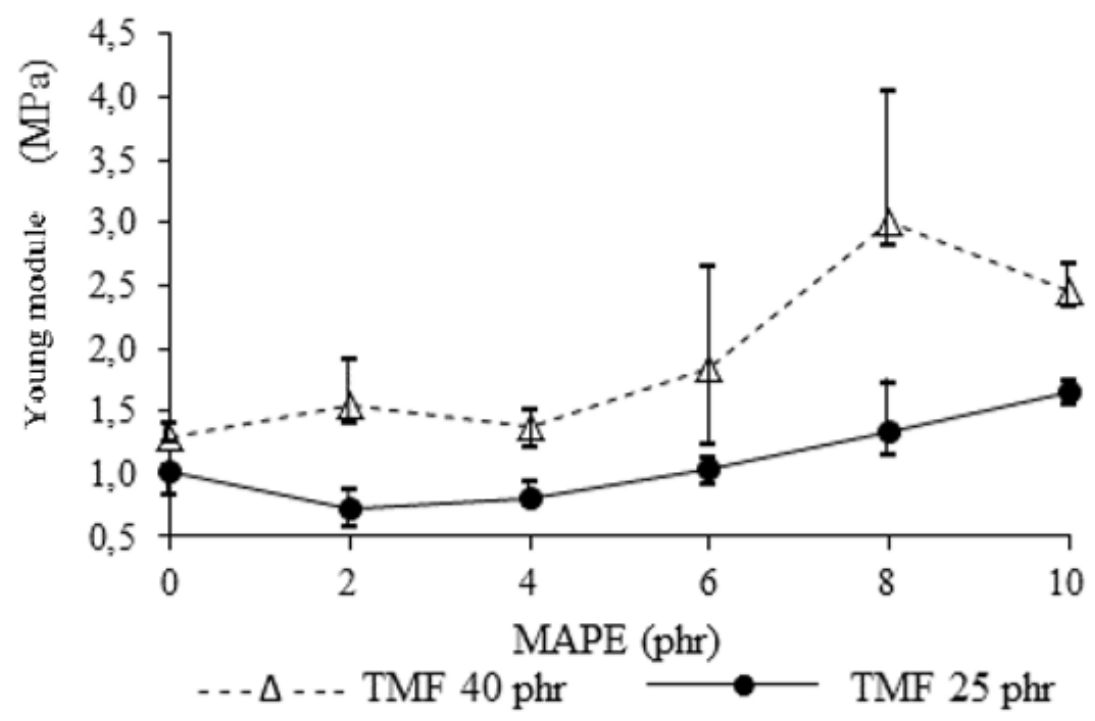

Figure 2. Young module of NR compounds. Effect of MAPE and TMF content.

The NR compounds with $40 \mathrm{phr}$ of TMF presented higher Young module values for compounds with $25 \mathrm{phr}$ of flour, independent of the amount of MAPE incorporated (see Figure 2). The increase in the concentration of TMF produced an increase in the stiffness of the compounds, a result that was in line with several investigations ${ }^{[26-28]}$. The increase in the level of MAPE also favors an increase in the modulus of elasticity. The effect of MAPE is only significant from 8 phr in both compounds having 25 and 40 phr of TMF. The compound module with 40 phr of fiber and 6 phr of coupling agent presented high dispersion of data, which does not allow to consider it as different from the compound without MAPE.

The highest value of the module was obtained with 40 phr of fiber and 8 phr of MAPE, being $130 \%$ higher with respect to the compound without coupling agent. The decrease in stiffness in the compound that has $40 \mathrm{phr}$ of TMF and $10 \mathrm{phr}$ of MAPE may be related to the decrease in cross-linking density (see Figures 1 and 2). 


\section{Tensile strength.}

When analyzing the effect of the coupling agent on the compounds made with $25 \mathrm{phr}$ of TMF, it was found that the tensile strength is significantly higher from 8 phr. Clearly the addition of the coupling agent improved stress transfer in the rubber compound. The compound data with 4 phr of coupling agent were very scattered.

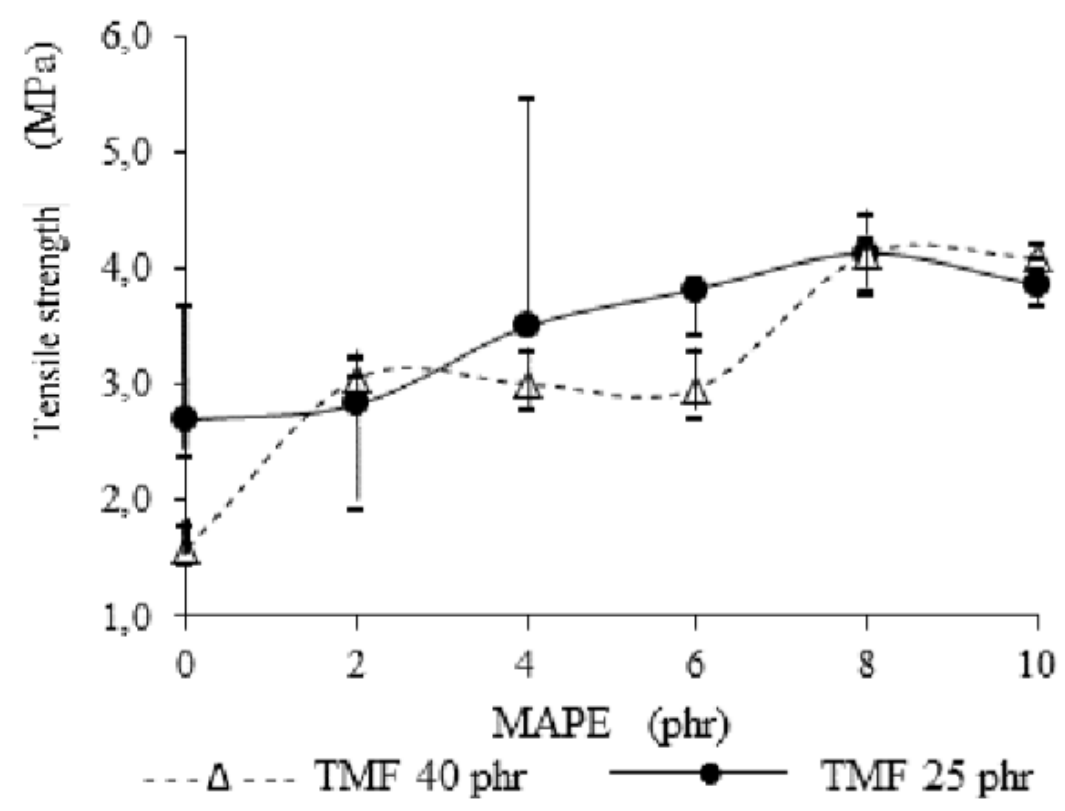

Figure 3. Tensile strength of NR compounds. Effect of MAPE and TMF content.

The compounds that have $40 \mathrm{phr}$ of TMF, presented an increase tensile strength starting from $2 \mathrm{phr}$ of MAPE. The maximum value of the tensile strength was presented in the compounds that have 8 phr of MAPE being 4,20 Mpa for $25 \mathrm{phr}$ of TMF and 4,16 Mpa in the compound that has $40 \mathrm{phr}$ of flour. Both tensile values turn out to be similar, however when compared with the respective compounds without MAPE, it is observed that the increase was $53 \%$ and $169 \%$ for compounds with $25 \mathrm{phr}$ and $40 \mathrm{phr}$ of flour respectively.

The incorporation of maleate improved the tensile strength, being more effective in the coupling of compounds made with $40 \mathrm{phr}$ of TMF. The results are consistent with the research carried out by Felix et $\mathrm{al}^{[29]}$ and $\mathrm{Lu}$ et $\left.\mathrm{al}^{[30}\right]$ who indicated that tensile strength improved due to the incorporation of maleate-type coupling agents in compounds made from natural fibers. 


\section{Elongation at Break.}

The behavior of this property is affected by TMF factors, MAPE and gel percentage (see Figures 1 and 4). The compounds made with $25 \mathrm{phr}$ of TMF have greater elongation compared to those with $40 \mathrm{phr}$ of flour, for any level of MAPE. This result is expected because the increase in flour concentration involves less polymer in the mixture and more likely to find fault sites in the fiber-rubber interface.

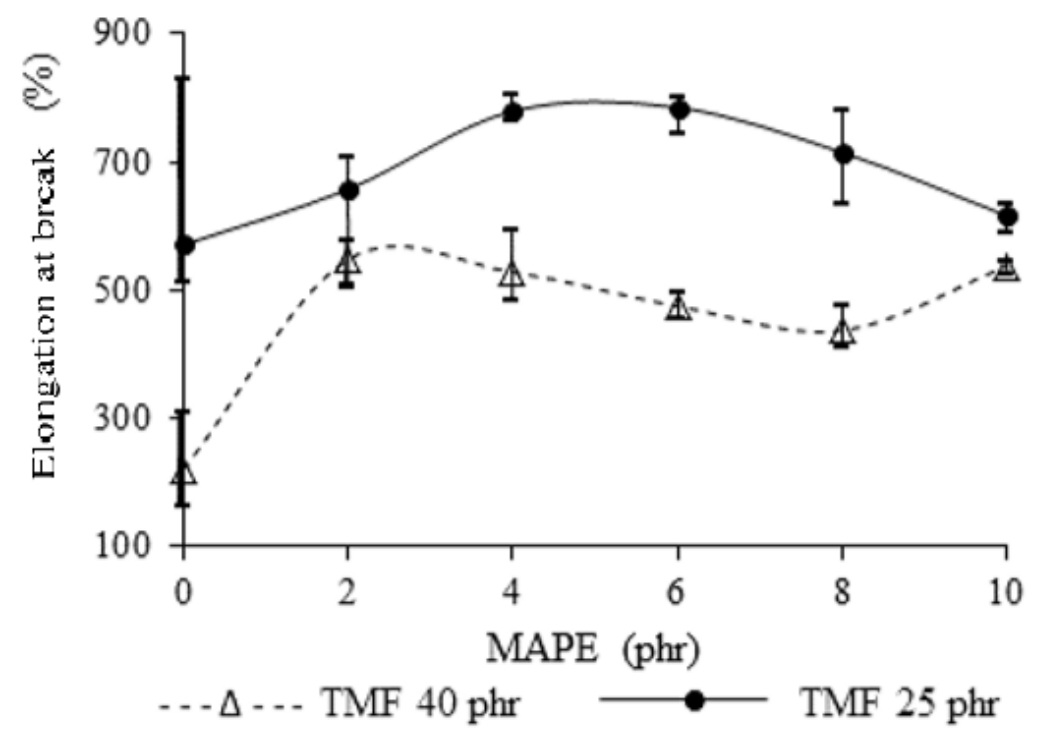

Figure 4. Elongation at break of NR compounds. Effect of MAPE and TMF content.

The effect of the incorporation of the coupling agent in compounds having $25 \mathrm{phr}$ of TMF indicates that despite the variation seen in Figure 4, it is not possible to conclude that the changes were significant due to the high dispersion of data in the compound without MAPE.

Compounds that have MAPE with 40 phr of fiber showed increased elongation compared to test zero. Carefully analyzing the range of compounds with MAPE (2-10 phr) it is observed 
that: the compound with $8 \mathrm{phr}$ of MAPE has less elongation in comparison to MAPE tests 2 and 4 whose difference may also be due to the restriction of movement due to the coupling, since in the $8^{\text {th }}$ the maximum traction value was produced.

The increase of the elongation at break of the compounds with $10 \mathrm{phr}$ of MAPE, regarding to the formulations with 6 and $8 \mathrm{phr}$, is possibly related to the decrease of the degree of crosslinking of the mixtures (see Figures 1 and 4). In theory, by decreasing the degree of crosslinking of the polymer chains, the elongation at break of the compound increases.

\section{Energy to Rupture.}

The compounds with $25 \mathrm{phr}$ of TMF showed increased tenacity in the range 4-8 phr of MAPE. This is related to the results of traction and elongation, it must be remembered that the tenacity or energy required to break the rubber compound mathematically is the area under the strain curve vs deformation. (See Figure 3). Regarding to compounds having $40 \mathrm{phr}$ of TMF, the tenacity increased by the effect of the addition of MAPE (2-10 phr). The maximum burst energy value was achieved with the addition of $10 \mathrm{phr}$ of MAPE, having a 500\% increase over the zero MAPE test, due to the very low energy value of the test without MAPE. An interesting endpoint arises at the $10 \mathrm{phr}$ level of MAPE where the tenacity values were similar for 25 and 40 phr of TMF.

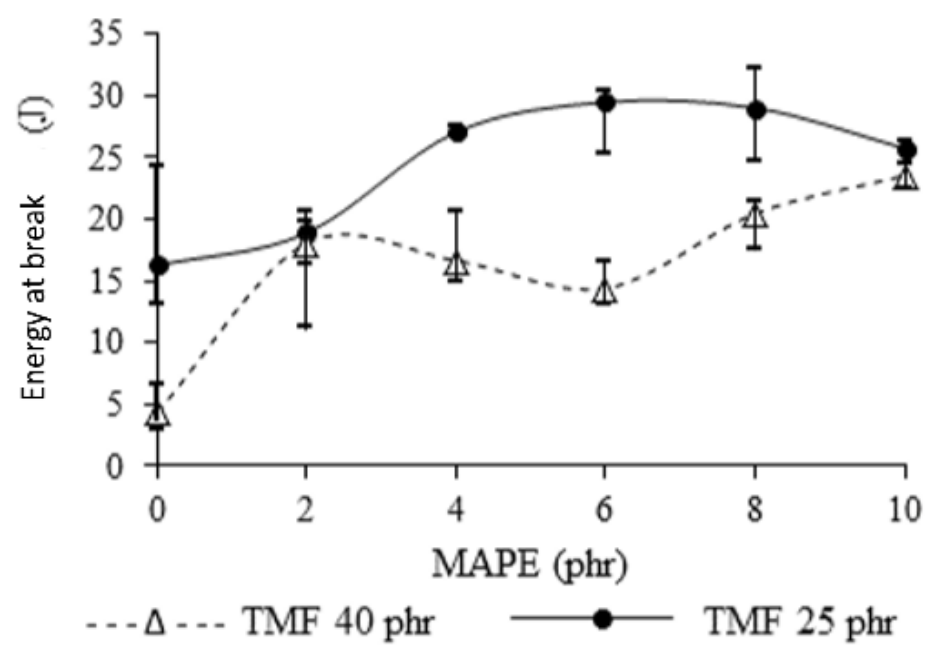


Figure 5. Tenacity of NR compounds. Effect of MAPE and TMF content.

An interesting endpoint emerges at the $10 \mathrm{phr}$ level of MAPE where the tenacity values were similar for 25 and $40 \mathrm{phr}$ of TMF.

\section{Hardness}

The hardness behaviour of NR compounds was affected by TMF and MAPE factors, as seen in Figure 6.

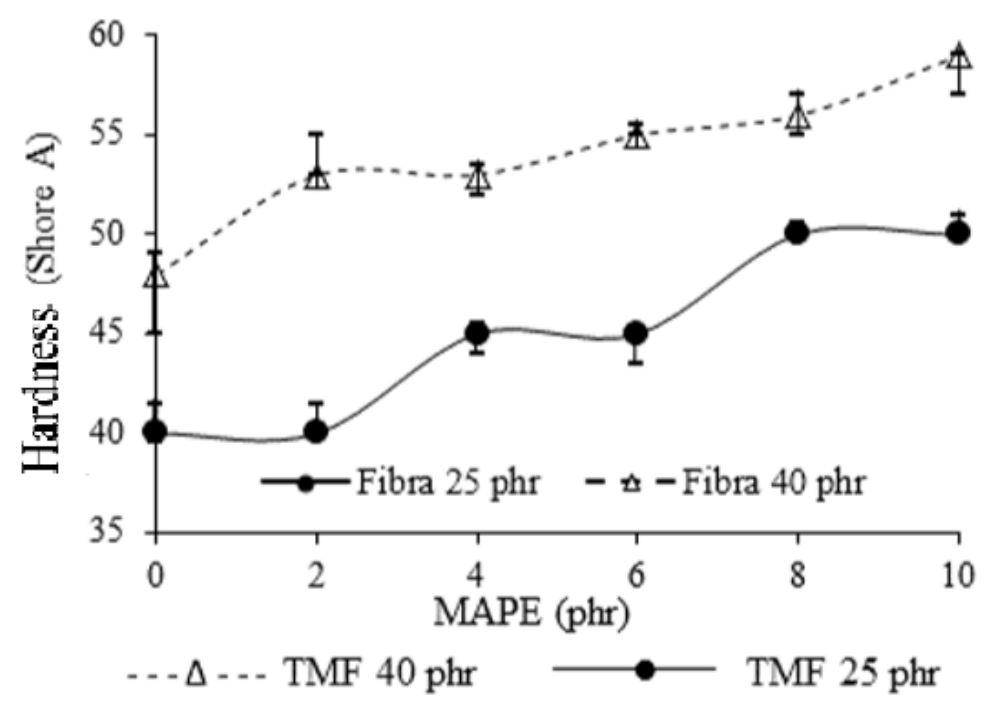

Figure 6. Hardness of NR compounds. Effect of MAPE and TMF content.

The compounds made with $40 \mathrm{phr}$ of TMF, presented greater hardness regarding to those of $25 \mathrm{phr}$, for any level of MAPE. This confirms the intrinsic contribution of hardness provided by natural fibre. The hardness as well as the viscosity of the NR decreases when subjected to shearing and temperature during mixing. The hardness of natural rubber (without TMF and additives) subjected to a mixing cycle according to the previously described methodology was very low and could not be measured using the Shore durometer. Due to the above, The addition of more TM flour promotes an increase hardness of the NR compound.

Analyzing the compounds from the standpoint of incorporating the coupling agent, it was found that the hardness increased gradually and proportional to the content of MAPE, a situation that was similar for 25 and $40 \mathrm{phr}$ of TMF. The intrinsical contribution of the 
hardness of MAPE ( $>95^{\circ}$ Shore A) to the NR compound is evident. The addition of 8-10 phr MAPE increased hardness by 10 and $9{ }^{\circ}$ Shore A for compounds made with 25 and 40 phr TMF respectively.

\section{Conclusions}

The addition of MAPE improved compatibility between Telinne Monspessulana flour and natural rubber. The improved wetting between vegetable flour and the polymer matrix, achieved with the use of the coupling agent, improved the transfer of stresses into the material as reflected in the increased tensile strength, elongation, toughness and hardness of the rubber compound regarding to the compound without MAPE; however, the decrease in gel content in some formulations regardless of the content of coupling agent clearly indicates that the simultaneous addition of MAPE and DCP, gives rise to competing reactions between the coupling of the MAPE functional groups and the hydroxyl groups in the cellulose and the crossing process of the polymer, reducing the density of the DCP-lattice rubber chains, affecting the mechanical properties of the rubber compound.

Regarding to the reinforcing load content, although the higher amount of flour, the more stiffness of the material increase its Young's modulus, this condition restricts the mobility of chains in the polymer, decreasing both the material elongation before a certain tension and the amount of energy it absorbs before its break.

\section{Acknowledgments}

This study is part of the research project INV-ING-1546, which has been funded by the Vicerectory of Research of the Universidad Militar Nueva Granada. Effective 2014.

\section{Bibliography.}

1. Faruk O, Bledzki AK, Fink H-P, Sain M. -Prog Polym Sci, 37(11), p. 1552 (2012). 
2. Li X, Tabil LG, Panigrahi S. -J Polym Environ, 15(1), p. 25 (2007).

3. Kabir MM, Wang H, Lau KT, Cardona F. -Compos Part B Eng. 43(7), p. 2883 (2012).

4. Keener TJ, Stuart RK, Brown TK. -Compos Part Appl Sci Manuf., 35(3), p. 357 (2004).

5. Ismail H, Rusli A, Rashid AA. -Polym Test., 24(7), p. 856 (2005).

6. Da Costa HM, Visconte LLY, Nunes RCR, Furtado CRG. -J Appl Polym Sci., 76(7), p. 1019 (2000).

7. Maziad NA, EL-Nashar DE, Sadek EM. -J Mater Sci., 44(10), p. 2665 (2009).

8. Yang H-S, Wolcott MP, Kim H-S, Kim S, Kim H-J. -Compos Struct. 79(3), p. 369 (2007).

9. Arifuzzaman Khan GM, Alam Shams MS, Kabir MR, Gafur MA, Terano M, Alam MS. J Appl Polym Sci., 128(2), p. 1020 (2013).

10. Jacob M, Thomas S, Varughese KT. -Compos Sci Technol., 64(7-8), p. 955(2004).

11. Geethamma VG, Thomas Mathew K, Lakshminarayanan R, Thomas S. -Polymer., 39(67), p. 1483 (1998).

12. $\mathrm{Xu} \mathrm{ZH}$, Kong $\mathrm{ZN}$. Mechanical and thermal properties of short-coirfiber-reinforced natural rubber/polyethylene composites. Mech Compos Mater. 50(3), p. 353 (2014).

13. Zeng Z, Ren W, Xu C, Lu W, Zhang Y, Zhang Y. -J Polym Res, 17(2), p. 213 (2010).

14. Ismail H, Rusli A, Azura AR. -J Polym Environ., 15(1), p. 67 (2007).

15. Ismail H, Rusli A, Rashid AA. -Polym Test., 24(7), p. 856 (2005).

16. Nakason C, Kaesaman A, Samoh Z, Homsin S, Kiatkamjornwong S. -Polym Test., 21(4), p. 449 (2002).

17. Benmesli S, Riahi F. -Polym Test., 36, p. 54 (2014).

18. Sameni JK, Ahmad SH, Zakaria S. -Adv Polym Technol., 23(1), p. 18 (2004). 
20. ASTM. - “ASTM D 2765-01 - Standard Test Methods for Determination of Gel Content and Swell Ratio of Crosslinked Ethylene Plastics” (2001).

20. ASTM. - “ASTM D 638-02 - Standard Test Method for Tensile Properties of Plastics" (2002).

21.ASTM.-“ASTM D2240-05 - Standard Test Method for Rubber Property-Durometer Hardness" (2010).

23. Wang, Y.-J.; Liu, W. \& Sun, Z. - J. Appl. Polym. Sci., 92(1), p.344 (2004).

24. Prachayawarakorn, J.; Khunsumled, S.; Thongpin, C.; Kositchaiyong, A. \& Sombatsompop, N. - J. Appl. Polym. Sci., 108(6), p. 3523 (2008).

25. Sameni, J.K.; Ahmad, S.H. \& Zakaria, S. - Adv. Polym. Tech., 23(1), p.18 (2004).

26. Arif MF, Megat-Yusoff PSM, Ahamad F.-J Reinf Plast Compos., 29, p. 2105 (2009).

27. Bengtsson M, Oksman K. -Compos Part A., 37, p. 752 (2006).

28. Salmah H, Faisal A, Kamaruddin H. -Int J Polym Mater 60, p. 429 (2011).

29. Felix, J.x. and Gatenholm, P.J. -J. Appl. Polym. Sci., 42, p. 609 (1999).

30. John Z. Lu, Ioan I. Negulescu, Qinglin Wu. -Composite Interfaces, 12, (1-2), p. 125 (2005).

31. T. Ozbakkaloglu, M. Saatcioglu-Displacement-based model to predict lateral drift capacities of concrete-filled FRP tube columnsEng.,pp. 345-355 147 (2017),

32. Y. Idris, T. Ozbakkaloglu - Behavior of square fiber reinforced polymer-high-strength concrete-steel double-skin tubular columns under combined axial compression and reversed-cyclic lateral loading,pp307-319, 118 (2016),

33. L.J. Ouyang, W.Y. Gao, B. Zhen, Z.D. Lu- Seismic retrofit of square reinforced concrete columns using basalt and carbon fiber-reinforced polymer sheets: a comparative study Compos., pp. 294-307162 (2017), 
